\title{
DOI 10.26886/2520-7474.4(48)2021.5
}

\section{UDC 7.012(045)}

GENERAL METHODS OF CONSTRUCTION OF OBJECTS WITH VARIABLE GEOMETRY IN OBJECTIVE-SPATIAL DESIGN

\section{Marta Hladchuk, PhD student}

https://orcid.org/0000-0002-4066-6371

e-mail: martagladchuk@gmail.com

Lviv Polytechnic National University, Ukraine, Lviv

The objective of the article is to define and characterize the basic general methods of construction of objects with variable geometry in the area of objective-spatial design.

On the basis of a thorough analysis of scientific publications and modern samples of transformative objects of different specifics, it was established that objects with variable geometry in objective-spatial design are often based on methods borrowed from architecture, design of mobile housing, clothing, etc.

As a result, ten general methods of transformation in objective-spatial design were defined, their characteristic features were described, the main areas of use and specificities of functional purpose were established.

The methods are as follows: the unfolding method (a partial or complete transfiguration of the initial form of the object, resulting in the unfolding of supplementary functional elements simultaneously or alternately); the packaging method (more radical version of the unfolding method); the rearrangement method (rearrangement of a set of modular elements in different ways, within the designs limits); the modular construction method (arrangement a set of subordinate modular parts in one or many particular ways to form a indivisible object); the displacement method (the process of shifting one or several parts of the initial structure in 
different directions relative to the static base); the rotation method (the movement of the structural elements of the object around its static base); the awning structures method (the construction of a closed environment by using pre-fabricated awning structures); the aggregation method (ensuring the variety of configurations of an object through a coalescence of its separate structural elements into an adjustable construction set); the unification method (unification of the vast variety of similar design objects and reduction it to a single form, system, configuration); the separation method (the splitting of one object into two or more self-sufficient parts).

In conclusion, it was established that in practice these ten methods are universal and have a wide range of applications, both utilitarian and conceptual in nature, and are often applied in different combinations in order to optimize the process of product exploitation, or to provide the necessary aesthetic characteristics.

Keywords: method of transformation, transformative design object, design, multifunctionality, mobility, design concept.

Introduction. Objects with variable geometry are widely used in many areas of design, meeting the demand for both utilitarian and conceptual design solutions. Despite the differences of the functionality, purpose and specificity of perception, the morphology of these objects is based on general methods of transformation. The study of these methods makes it possible to better understand the initial characteristics of the objects with variable geometry, their capabilities and the most appropriate areas of their use. The research of general methods is also a prerequisite for further defining specific methods of transformation for each individual area of objective-spatial design.

Analysis of recent research and publications. The analysis of scientific publications concerning the principles and methods of 
transformation showed the existence of a common methodological base for the construction of all objects with variable geometry, regardless of the scope of application.

Principles and methods of transformation in general in different areas are studied by Verhunova N.S. (Verhunova, 2015) (industrial design), Kaneva M. I. (Kaneva, 2007) (furniture design), Nagorna Z.V. (Nagorna, 2009) (clothing design), Panfilov A.V. (Panfilov, 2013) (design of mobile housing), Saprykina N.A. (Saprykina, 2005) (architecture).

Individual methods of constructing objects with variable geometry are highlighted by Gnatiuk L.R. and Draga M.L. (Gnatiuk and Draga, 2013), Kuznetsova I.A. and Sirak V.V. (Kuznetsova and Sirak, 2014), Shymanska T.A. (Shymanska, 2012), Marahovskyi A.A. (Marahovskyi and Shymanska, 2012), Stotsko R.Z. (Stotsko, 2014), Lisun I.S. (Lisun, 2014).

Objective of the article. The aim of the article is to define and characterize the basic general methods of construction of objects with variable geometry in the area of objective-spatial design as well as to establish the most appropriate ways of their practical application.

Main material. The purpose of use of any morphological method of constructing objects with variable geometry is to extend the functional limits of these objects, to change their dimensions, shape, appearance and, if necessary, to make them suitable for use in different environmental conditions. Due to the analysis of a wide range of modern samples of transformational objects, it was established that objects with variable geometry in the area of objective-spatial design are often based on methods borrowed from architecture, design of mobile housing, clothing, etc.

This article describes the 10 most common, effective, and versatile methods of morphological transformation in terms of their application in the area of objective-spatial design. All of the following methods are self- 
sufficient, but they are often used in various combinations to optimize the operation of the final product, to provide its necessary aesthetic characteristics, etc.

1. The unfolding method. It consists in a partial or complete transfiguration of the initial form of the object, resulting in the unfolding of all supplementary functional elements simultaneously or alternately. This method does not alter the main functions of the object, but rather complements, modifies its form, making it more suitable for performing particular functions [7, p. 18]. In case of this method, transformation results in a significant increase of the space of the object due to the use of various hidden (sliding, folding, stretching, etc.) surfaces and bulk elements. The dimensions of the item in its folded state must be compact in order to allow transportation, but sufficient enough to be able to contain all the functional supplements. The object in its initial form does not necessarily lose the ability to perform all its functions, but can only perform some of them. This method is most effective for constructing multifunctional design objects. It is often used to design high-end mobile houses, residential containers and complex furniture sets which serve as fully fledged functional zones. It is worth noting that unfolding and decomposition are a fundamental principles of functioning of transformed objects and are the basis of many of the methods listed below.

An example of the implementation of the unfolding method is project Cubitat (Fig. 1) by Luke Nichetto. It is a housing module with dimensions of $3 \times 3 \times 3$ meters, which consists of all the necessary elements to equip several functional zones: bedroom, kitchen, bathroom and zones for rest and storage. Part of the zones are located inside the cube (bathroom and storage) and the rest are evenly distributed on 4 outer sides. 

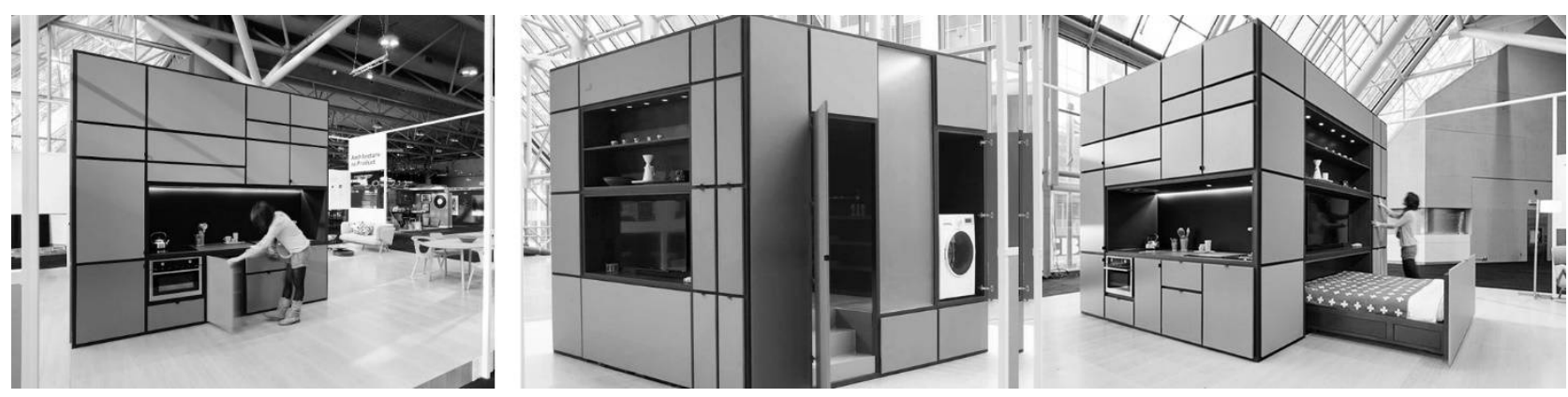

Fig. 1. The unfolding method. Housing module Cubitat by Luke Nichetto

2. The "packaging" method. It is based on the unfolding method, but it is more radical. Its purpose is to produce a variable geometry object with the maximum compact initial dimensions possible in order to provide a high level of transport mobility. In most cases, such objects lose their ability to perform all of their functions during transportation and change their shape and size drastically after transformation. The entire internal space of the initial form of the object is used to store all the supplements and auxiliaries. For the most part, objects constructed using this method have a simplified geometric shape (such as a cube or parallelepiped) which allows the most efficient use of space within the initial form, as the main focus is on functionality, and not the figurative solution. In objective-spatial design this method is widely used to design compact mobile furniture and equipment.

An example of a project based on the packaging method are furniture transformers from the Japanese company Kenchikukagu (Fig. 2). These are compact furniture sets with a high level of mobility, which in their initial form resemble relatively small parallelepipeds on wheels, and in the transformed state perform the functions of different functional zones: bedroom, kitchen and workplace. 

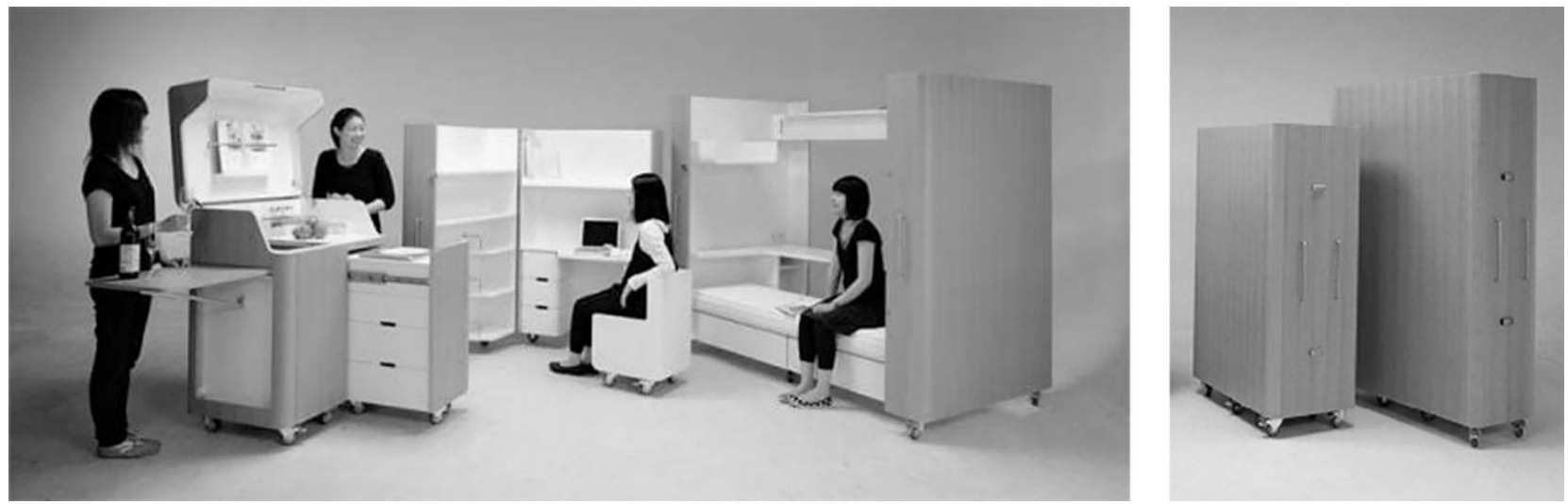

Fig. 2. The "packaging" method. Kenchikukagu furniture transformers

3. The rearrangement method. It consists in rearranging a set of identical or similar modular elements in different ways, depending on the need and within the designed functions and, accordingly, is based on the principle of combinatorics. Modules can be either separate self-sufficient objects or parts of an indivisible whole. Transformation occurs not due to the direct transfiguration of the separate elements, but through the variation of their layout. The functions and the semantic load of the project are entirely dependent on the number of modules, their placement and the structural links between them and may change drastically after every transformation session. This method is actively used both for design of furniture for residential interiors, and for design of public spaces of various purposes (for example, exhibition spaces, installations, kinetic sculpture, etc).

An example of the use of the rearrangement method is the modular sofa"Idea Fix (Fig. 3). It consists of 12 frameless textile pillows measuring $67 \times 67 \times 22 \mathrm{~cm}$, with velcro straps and covers, which fasten the modules together. The 12 individual modules provide extensive combinatorics possibilities, allowing one to create sofas of different configurations, individual poufs, coffee and bedside tables, single or double beds and more. 

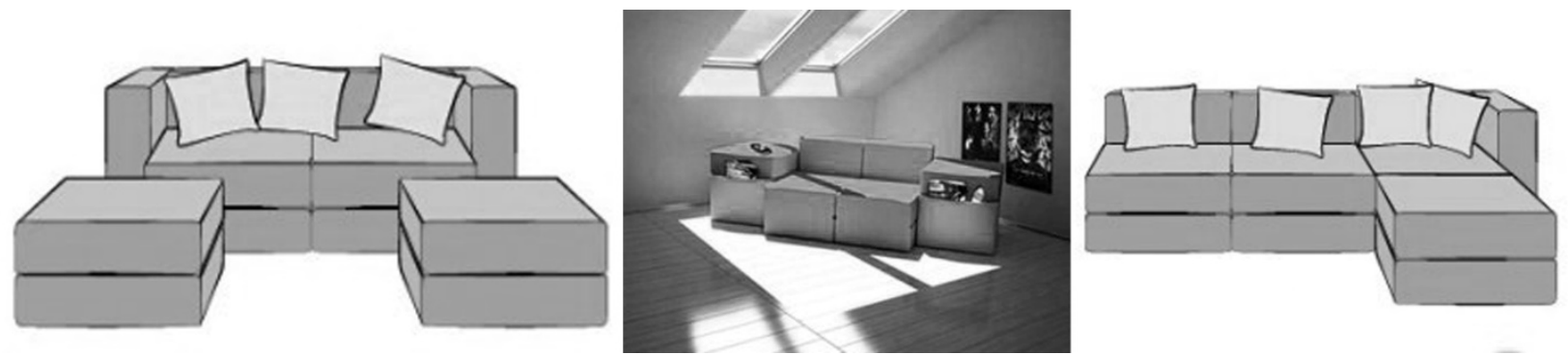

Fig. 3. The rearrangement method. Modular sofa Idea Fix

4. Modular construction method. It is similar to the rearrangement method, however, with significant differences. In this case, modular parts are not considered as self-sufficient elements, but solely as constituents of an indivisible whole. This means, that the individual modules do not carry any functional and semantic value and without conjunction with other parts look unfinished. This kind of "splitting" the whole object into elements is often used in installation.

An example of modular construction is the ANYПAKOH installation (Fig. 4) of the INI studio, presented at the London Design Biennale in 2018. The design looks like a 17-meter narrow corridor consisting of a rigid steel frame and flexible recycled plastic modules. The modules are attached to the frame in such a way that it moves smoothly as a person walks through the corridor, creating a sense of wavy, impulse dynamics of space.
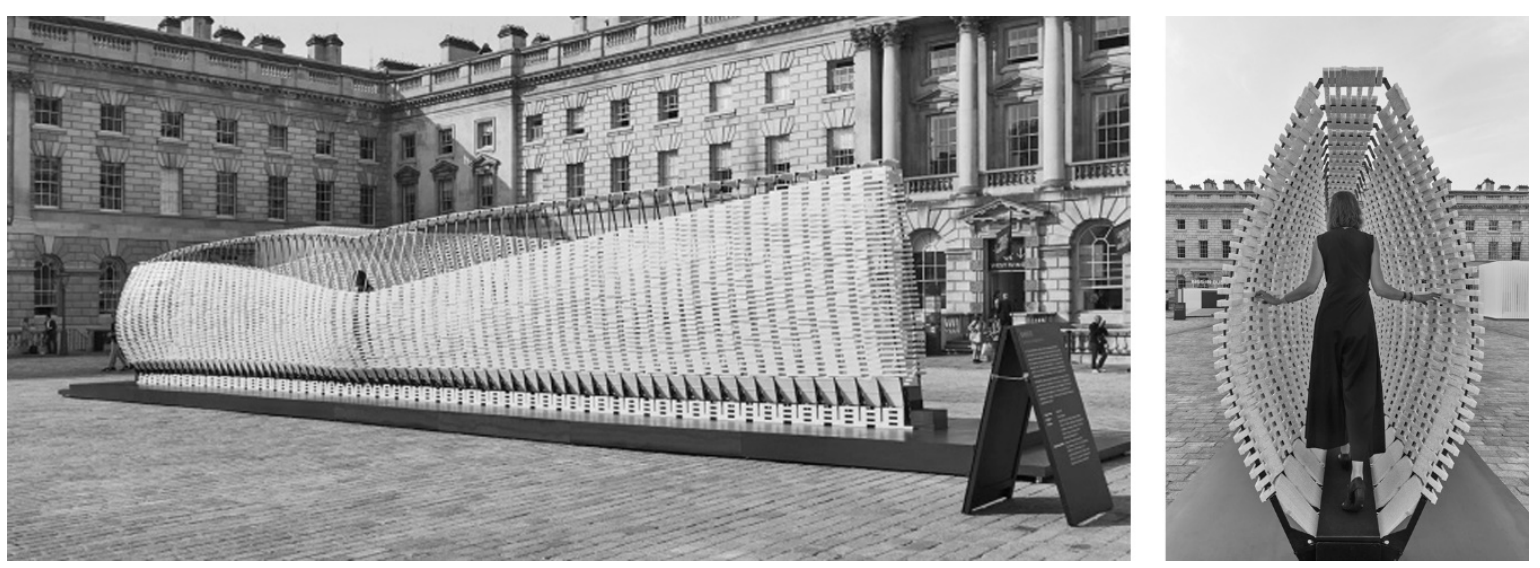

Fig. 4. Modular construction method. ANYחAKOH installation by INI studio, London Design Biennale, 2018 
5. The displacement method. It consists in shifting one or several parts of the initial structure in different directions relative to the static center or base. Displaced parts remain attached to the base. This method allows to dramatically change the original shape and dimensions of the object. Displaced parts can be connected by sections of elastic materials that eventually act as partitions and fasteners, or move arbitrarily along a joint system of guide rails. The use of this method often causes a sense of disruption of the environmental, which determines its popularity in the areas of exhibition design, installation and kinetic sculpture.

An example of applying the displacement method are the "living" sculptures (Fig. 5) by Li Hongbo, made of paper and based on the technique of Chinese lanterns. The material for the sculpture is specifically glued into dense paper blocks, which are treated by the author like a stone. At first glance, sculptures look like classic gypsum busts, however, after the displacement of a certain part of the block, the whole sculpture deforms, drastically changing its shape [12, p. 261].
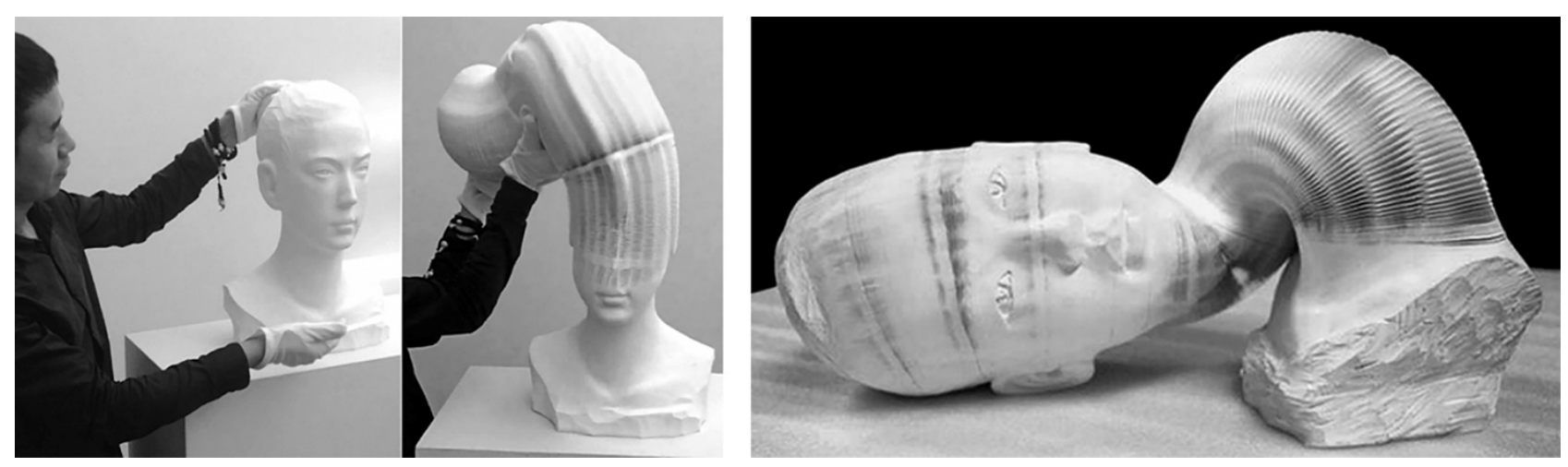

Fig. 5. The displacement method. The "living" sculptures by Li Hongbo

6. The rotation method. This method consists in the movement of the structural elements of the object around its static base which operates as the axis of rotation. All structural elements are connected to the base within this axis, and the rotation of the elements changes the shape of the object, revealing additional elements and functions, as well as shifts its figurative 
image, providing possibilities of alternative interpretations of the object's meaning. From a utilitarian point of view, this method of transformation is capable of providing a significant increase in the size of the object, the extent of which depends on the number and shape of the moving tiers attached to the base. From the figurative - it has considerable conceptual potential, which allows to express the dynamics and volatility of objects in a ostensive way. Due to this features, the rotation method has a very wide range of applications: from architecture of buildings and structures, design of mobile housing, furniture and equipment to kinetic sculpture.

An example of an object with variable geometry constructed on the basis of the rotation method is a kinetic monument to Franz Kafka, located in Prague, created by sculptor David Czerny. This monumental mirror bust consists of 42 layers made of stainless steel which rotate independently from one another, periodically aligning so that the portrait image becomes recognizable.
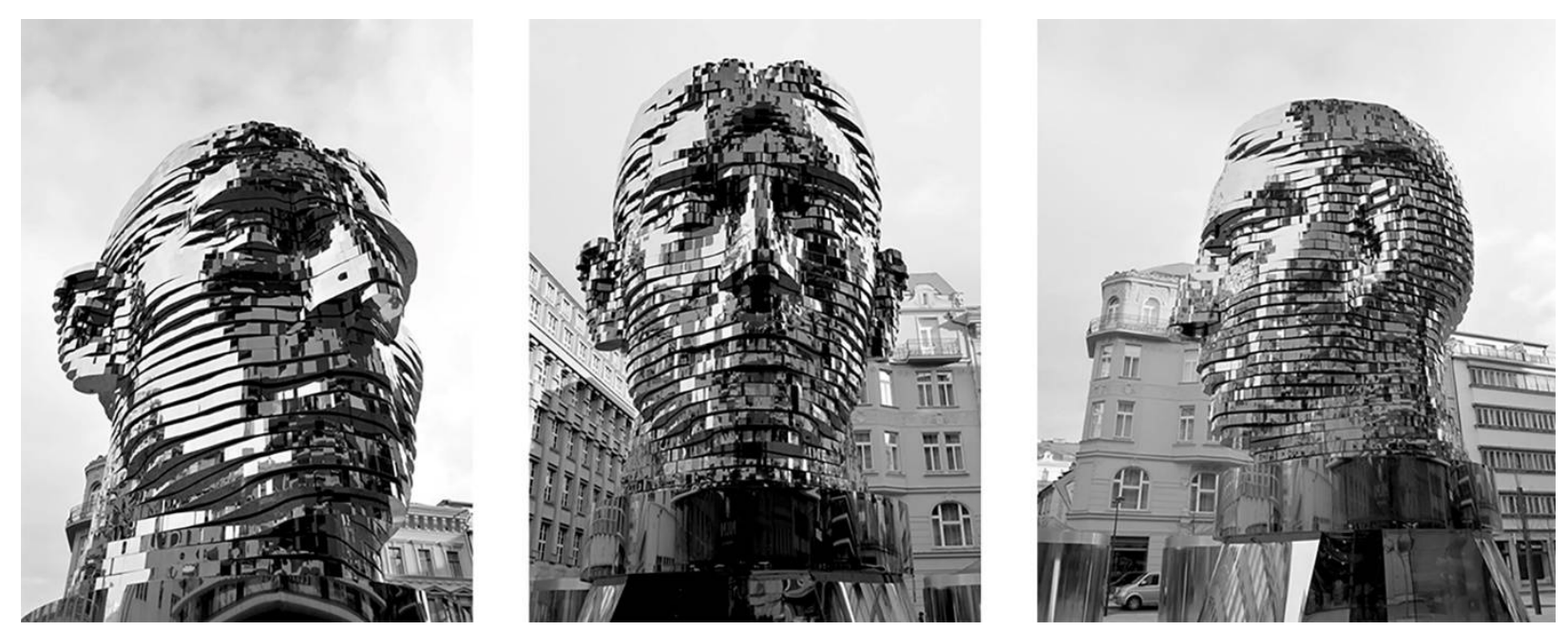

Fig. 6. The rotation method. Kinetic monument to Franz Kafka, Prague, David Czerny

7. The awning structures method. It consists in the construction of a closed environment by stretching a fabric or elastic polymer material onto the collapsible frame, or by the use of pre-fabricated awning structures with a build-in frame of a predetermined shape. Usually, this method is not used 
alone, but acting as an auxiliary elements of the object (exception: tent). Based on the analysis of analogues, awning structures by construction can be divided into 4 main groups: with a built-in fan frame; with a built-in accordion frame; with a built-in sail frame; without a built-in frame.

This method is widely used to create temporary housing ranging from conventional tents to conceptual hotel complexes. Also, awning structures play an auxiliary role in design of the public exteriors and interiors.

An example of a variable geometry object based on awning structures is the Xiringuito Margate mobile restaurant (Fig. 7), developed by Asif Khan architectural studio. The construction consists of a modular metal frame and awning cover, and can be mounted in a form of a straight line, wave, curve or circle (depending on the wishes of the customer).
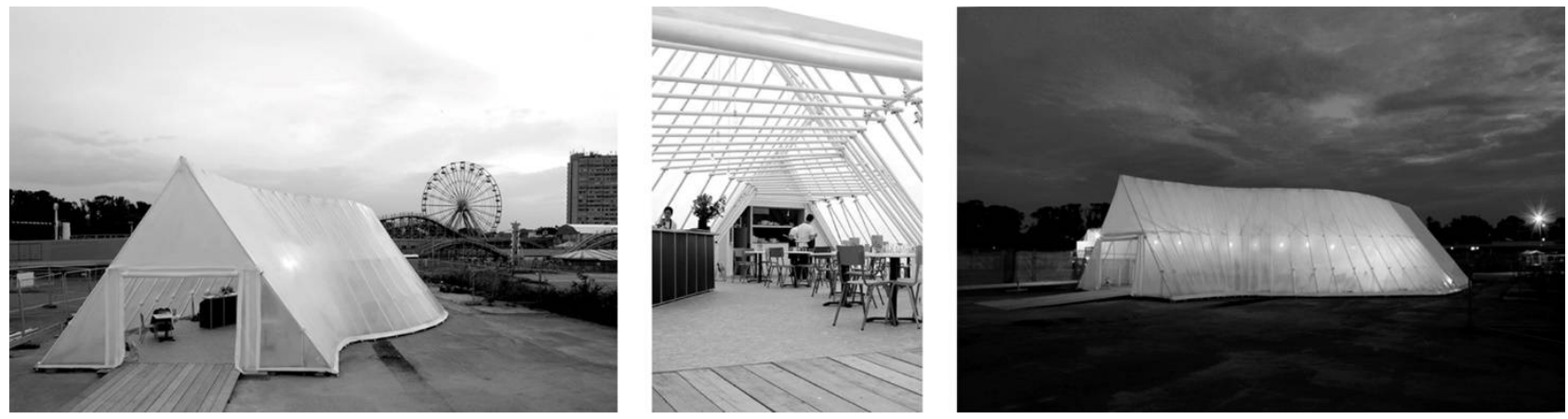

Fig. 7. The awning structures method. Xiringuito Margate mobile restaurant, Asif Khan

8. The aggregation method. The main purpose of this method is to ensure the improvement of quality of the object and the expansion of the variety of its configurations within a single design. It happens through a coalescence of all separate structural elements of the transformational object into one. This method results in creating of a construction set - a holistic structure which consists of a particular number of modular parts which can be connected and rearranged at predefined nodes. 
Construction set objects are classified into three main types: basic modifications construction set; standard size construction set; aggregate (modular) construction set [8, pp. 205-206].

Collapsible aggregate systems provide a variable approach to building the final configuration of an object. The aggregation method is one of the key methods of the design of objects with variable geometry of mass production (modular furniture).

An example is an aggregate construction set, namely modular shelves by Clive Wilkinson installed in the Disney Store Headquarters office (Fig. 8). Shelves consist of a large number of identical cell modules that connect at predefined nodes, but ultimately form an arbitrary composition.
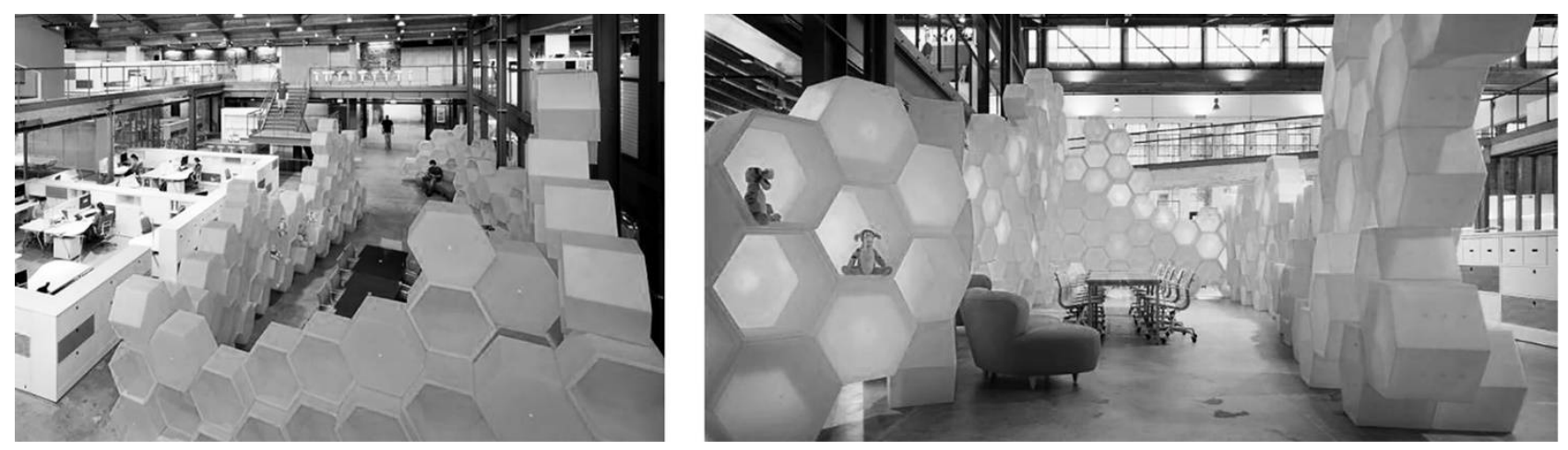

Fig. 8. The aggregation method. Modular shelves installed in the Disney Store Headquarters office, Clive Wilkinson

9. The unification method. This method is aimed to unify the vast variety of similar design objects and reduce it to a single form, system, configuration. Standardization, normalization and unification help to accelerate the technological process and increase the efficiency of production process and use of a final product. At present, unification is implemented in design in the following ways:

- typical - carried out by the creation and mass production of unified series of homogeneous products, with basic models and modifications; 
- intertypical - achieved through the creation and use of the same mass-produced unified elements (units, modules and spare parts) in various heterogeneous products [9, pp.149].

Unification is an important principle of constructing mass produced design objects, as well as unique modular systems that need to be reduced to a single configuration, with subsequent arrangement in metric or rhythmic series. Therefore, the unification is used in industrial design of objects of different specifics, as well as in installation design.

For example, a typical table-transformer, which changes from a coffee table to a dining table and vice versa (Fig. 9).
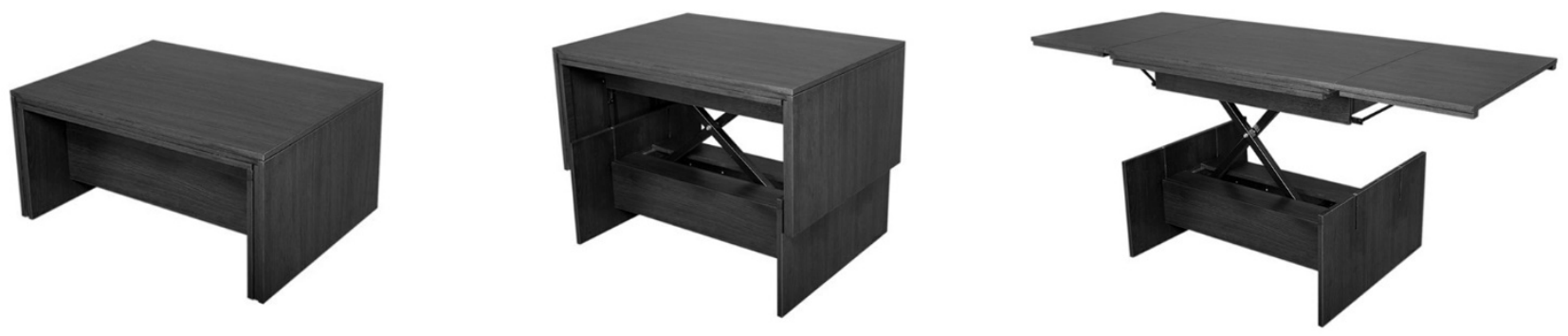

Fig. 9. The unification method. Table-transformer A-1, Dlya Vas

10. The separation method - consists in the splitting one object with variable geometry into two or more parts, each of which acquires selfsufficiency and performs adjacent or completely different functions. It is worth noting, that in many of the above-mentioned methods, the moment of separation is also present, but in this case, transformation results in creation of completely separate, in no way interconnected objects. This method is widely used in furniture design. 

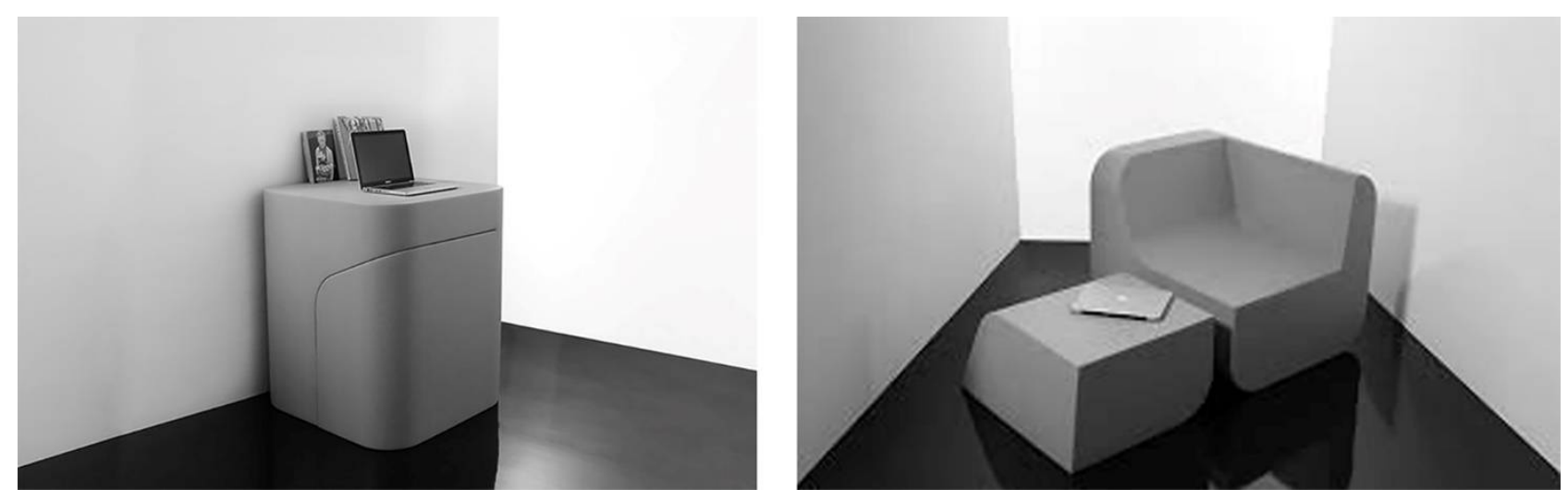

Fig. 10. The separation method. 4-in-1 Furniture System, Kitmen Keung

An example of a project based on the separation method is the 4-in-1 Furniture System (Fig. 10) by Chinese-Canadian designer Kitmen Keung. In its initial form, the object acts as a corner table, and in transformed form it acquires two configuration options: a couch or a chair with a coffee table.

Conclusions. The ten methods of constructing objects with variable geometry in the field of objective-spatial design, which are described in this article, are universal and have a wide range of applications, both utilitarian and conceptual in nature. The choice of method of transformation is vastly determined by the functional purpose and conditions of use of the finale product. The analysis of modern samples of transformational objects of different specifics showed that, despite the self-sufficiency, in practice these ten methods are often applied in different combinations in order to optimize the process of product exploitation, to provide the necessary aesthetic characteristics, etc. Further research will be focused on identifying the application features of these methods and their specific modifications in the fields of conceptual design and art.

\section{References:}


1. Verhunova, N. S., (2015). Transforming principles and its definitions in the industrial design sphere. Visnyk Kharkivskoi derzhavnoi akademii dyzainu i mystetstv. Dyzain: istoriia, teoriia i praktyka, 7, pp. 9-14.

2. Kaneva, M. I., (2007). Furniture-transformer. Historical prototypes of interactive furniture of the future. St. Petersburg: Noosfera SPb.

3. Nahorna, Z. V., (2009). Classification of methods of transformation forms in design of clothes. Visnyk Kharkivskoi derzhavnoi akademii dyzainu $i$ mystetstv. Dyzain prostorovo-predmetnoho seredovyshcha, 74, pp. 87-89.

4. Panfilov, A. V., (2013). Features of the formation of mobile housing for temporary stay (end of XXth - beginning of the XXIst century). Thesis abstract for Cand. Sc.: 05.23.21, Moscow, 26 p.

5. Saprykina, N. A., (2005). Fundamentals of dynamic shaping of architectural objects. Moscow: Arkhitektura-S.

6. Gnatiuk, L. R. and Draga, M. L., (2013). Features modular shaping transformer furniture. Teoriia ta praktyka dyzainu, 3, pp. 15-22.

7. Kuznetsova, I. A. and Sirak, V. V., (2014). Features motion in interior design. Visnyk Kharkivskoi derzhavnoi akademii dyzainu i mystetstv. Teoriia ta istoriia dyzainu, 3, pp. 15-19.

8. Shymanska, T. A., (2012). Features of forming objects in transformable design. Nauka i molod. Prykladna Seriia, 11-12, pp. c. 204-207.

9. Marahovskyi, A. A. and Shymanska, T. A., (2012). Transforming objects in design. Teoriia ta praktyka dyzainu, 2, pp. 148-154.

10. Stotsko, R. Z., (2014). Features of architecture of buildings of higher education institutions with variable geometry. Arkhitekturnyi visnyk Kyivskoho natsionalnoho universytetu budivnytstva $i$ arkhitektury. Arkhitektura budivel ta sporud, 2, pp. 384-391.

11. Lisun, I. S., (2014). The transformed folded structures in construction. Teoriia ta praktyka dyzainu, 6, pp. 108-116. 
12. Hladchuk, M. Yu., (2019). Modern trends of application of transformational shape-forming in the objective-spatial design. Naukovi zapysky Ternopilskoho natsionalnoho pedahohichnoho universytetu imeni V.Hnatiuka. Seriia: Mystetstvoznavstvo, 1 (40), pp. 256-267.

Citation: Uliana Khamar (2021). THE ANIMAL WORLD IN THE LIGHT OF ANCIENT CHINESE PHILOSOPHY. Frankfurt. TK Meganom LLC. Paradigm of knowledge. 4(48). doi: 10.26886/25207474.4(48)2021.5

Copyright Uliana Khamar (C). 2021. This is an openaccess article distributed under the terms of the Creative Commons Attribution License (CC BY). The use, distribution or reproduction in other forums is permitted, provided the original author(s) or licensor are credited and that the original publication in this journal is cited, in accordance with accepted academic practice. No use, distribution or reproduction is permitted which does not comply with these terms. 